\title{
Language experience in L2 phonological learning: Effects of psycholinguistic and sociolinguistic variables
}

PAVEL TROFIMOVICH

Abstract

The goal of this paper is to discuss language experience in second language (L2) phonological learning, with a particular focus on lexical frequency, attention to form, and ethnic identity as factors that influence the role of language experience. First, several difficulties associated with the study of language experience are discussed. Then, evidence is presented that lexical frequency, attention to form, and ethnic identity interact with measures of language experience, thereby shaping positive and negative effects of experience on L2 phonological learning. Next, it is argued that language experience and L2 learning outcomes are linked through bi-directional, reciprocal relationships. The paper concludes with a discussion of several avenues of future research for the study of language experience in L2 phonological learning.

\section{Introduction}

Most researchers and practitioners in the field of second language (L2) acquisition would agree that language experience plays an important role in L2 learning. This idea is not new. For example, the importance of learners' experience with a language was emphasized in the writings of the 17th century educator Comenius (Musumeci 1997) and in the works of the applied linguist Harold E. Palmer in the early 20th century (Palmer 1917 [1968]). Linguistic experience, and in particular learners' engagement with linguistic input, has also been central to various and more recent theoretical and applied approaches to L2 learning and teaching (e.g., see Piske and Young-Scholten 2009; VanPatten 2004). Common to all these approaches is the idea that success in L2 learning appears to depend on the exact nature and the extent of learners' experience with a language.

A great deal of research to date has been devoted to the study of just how learners experience language. Such research has examined, for example, how 
rich the linguistic information (input) to learners should be (e.g., Lightbown 1985), how learners process and internalize language input (e.g., Schmidt 2001), or what particular types of language practice are most beneficial to learners (e.g., De Graaf and Housen 2009; Howard 2005; Pérez-Vidal and Juan-Garau 2009). Although there has been some progress in understanding what kinds of language experiences lead to efficient L2 learning (e.g., see contributions to this volume), relatively little is known about the specific factors that influence how experience contributes to L2 learning. The goal of this paper is to discuss some of these factors with respect to L2 phonological learning. Defined broadly, phonological learning here refers to the process of learning the segmental and suprasegmental aspects of an L2. Throughout this paper, the terms "language experience" and "language use" are used interchangeably and refer to all situations in which learners engage with a language in a meaningful way through input and/or output outside the classroom.

\section{Studying language experience}

One of the biggest obstacles to understanding the role of experience in L2 learning is the difficulty of defining precisely what language experience means. Experience is a metaphor for a host of different activities, all describing learners' encounters with a language. In research on L2 phonological learning, for example, experience has often been defined as learners' length of residence in an L2 environment (e.g., Flege et al. 1995) or has been measured in terms of amount of learners' contact with native speakers (e.g., Purcell and Suter 1980; Thompson 1991), amount of L2 instruction (e.g., Flege and Fletcher 1992; Suter 1976), or the number of hours spent using a language in different modes, such as listening or speaking, and in different domains, including interactions with friends, colleagues, family members (e.g., Moyer 2006). Of course, much richer descriptions of language experience can be obtained through learners' ethnographic reports of language use (e.g., Piller 2002). However, none of these measures, taken individually or even combined, would be sufficient to tap into the depth and breadth of a person's meaningful encounters with a language.

Flege (2009) recently identified at least two other reasons for the difficulties associated with investigating the role of experience in L2 learning. One reason is that measures of experience are often confounded with a variety of other variables, which can conceal the contributions of language experience to L2 learning. Typically, measures of experience, such as length of residence or amount of L2 use, are strongly correlated with learners' age of first exposure to an L2 (see Muñoz 2006). However, measures of experience may also be related to a variety of other factors, including learners' individual differences in perceptual and cognitive abilities, their motivations, social orientations, educational level, 
socioeconomic status, and willingness to assimilate both linguistically and culturally (Flege et al. 1999; Jia and Aaronson 2003; Moyer 2004a; Piller 2002). These and other variables could influence the extent to which learners engage in meaningful use of language and as a result could moderate the effects of experience on L2 learning outcomes.

Another reason for the difficulty in investigating the role of experience in L2 learning is that experience is hard to measure experimentally, even when this variable is clearly defined for research purposes. In fact, Flege (2009) maintained that in most studies of L2 phonological learning, learners' experience with an L2 has been measured only indirectly, through participants' self-reports or scalar ratings. Such measurements, he argued, are error-prone and therefore unreliable. Perhaps the only exception to this generalization comes from the so-called first-exposure studies, or studies in which learners are observed in the earliest stages of learning, and in which learners' experience with linguistic input can be carefully controlled and measured (for review, see Rast 2008: Ch. 2). For instance, Gullberg et al. (forthcoming) recently showed that L2 learners could use several cues in the input, including phonology, to recognize words in an entirely unfamiliar language after merely minutes of exposure to it. Because first-exposure studies are scarce in the literature and because controlling language exposure beyond the very first hours or days of learning is challenging, if not utterly impossible, researchers have to grapple with other ways of investigating language experience experimentally.

The complexity of studying effects of experience can be illustrated by using an example from a recent study by Trofimovich et al. (2009). These researchers analyzed the pronunciation of two groups of child francophone learners of English in grades 3 and 4 . Both groups of learners came from predominantly francophone areas of New Brunswick, Canada, where opportunities for contact with English outside the school were minimal. One group was enrolled in a comprehension-based, experimental program. In this program, the learners experienced their L2 only through reading and listening activities. They read stories and other English material and listened to accompanying audio recordings. The learners proceeded through these activities at their own pace, working independently. They never took part in language lessons, completed tests, engaged in interaction with other students, or received feedback from teachers. The other group of learners participated in a regular aural-oral program taught by a teacher. In this program, the learners were engaged in common classroom activities, including question-and-answer tasks, dialogues, songs, and some reading and writing practice.

The learners in both programs were tested at the end of grades 3 and 4, and several pronunciation measures were obtained. Briefly, the results showed that the learners in the experimental and regular programs performed equally well on most measures, which suggested that at least two years of comprehension- 

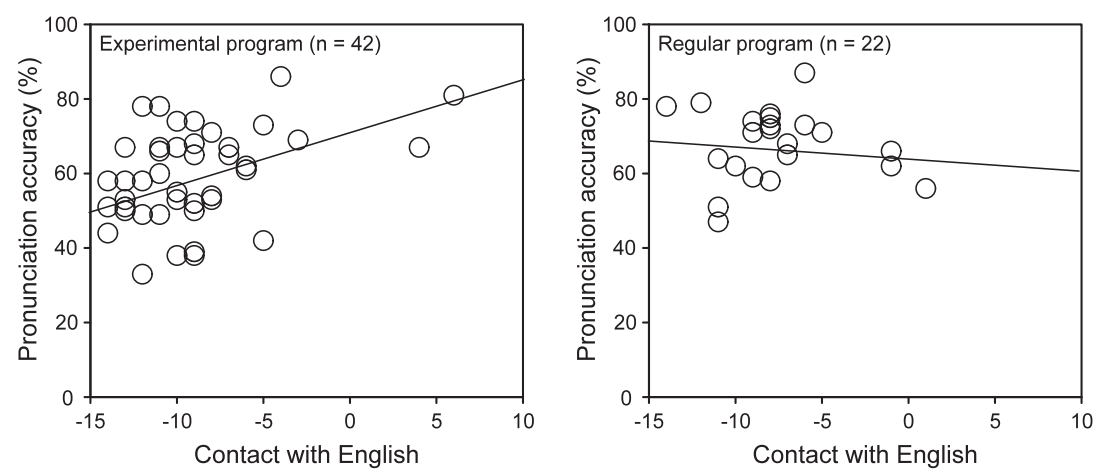

Figure 1. The relationship between francophone learners' L2 contact $(-14=$ no contact with English, $+14=$ much contact with English) and their sentence-based pronunciation accuracy scores (percent correct) at the end of grade 4 , with a regression line showing the best fit to the data (based on Trofimovich et al. 2009)

based experience, in the absence of any speaking practice inside the classroom, is not detrimental to the development of L2 pronunciation. However, a subsequent analysis of the learners' data revealed an interesting pattern of findings relevant to the present discussion. It was found that several pronunciation measures at the end of grade 4 were significantly associated with the degree of learner contact with English outside the school. Although opportunities for L2 contact were scarce and most learners reported relatively little contact with English outside the school, greater contact with English was associated with higher pronunciation scores. The striking finding, however, was that this relationship was found only for the learners in the experimental, but not the regular program. This is illustrated graphically in Figure 1, using as an example the learners' pronunciation accuracy scores from an elicited imitation task. For the learners in the experimental program, the correlation between pronunciation accuracy and contact with English was above chance, $r(40)=.39, p=.005$. For the learners in the regular program, no significant relationship of this kind was detected, $r(20)=-.01$.

The finding illustrated in Figure 1 is significant because it suggests that the benefits of L2 experience outside language instruction may depend on the kind of language practice learners receive inside the classroom. It is possible that the extensive reading and listening practice may have helped at least some learners in the experimental program to reach a level of English ability which allowed them to use English outside the school. This, in turn, provided them with chances to practice and improve their pronunciation. Alternatively, it is also possible that the learners who sought more opportunities for contact with 
English outside the school might have been those who benefitted the most from the rich comprehension-based practice they received through instruction. Whatever the precise nature of this relationship (a point which will be discussed in more detail below), the important finding was that this association between L2 contact and L2 pronunciation measures was not found for the learners who received more "typical", regular classroom instruction.

The finding that the type of instruction can interact with learners' language experience outside the classroom is not new. This possibility was raised a number of years ago by Spada (1986); a similar interaction was reported by Flege and Liu (2001), with length of residence used as a measure of L2 experience. One conclusion that can be drawn from these findings is that a variety of different factors can shape the role of experience in L2 phonological learning. The goal of the next section is to discuss three of these factors in greater detail.

\section{Factors that shape $L 2$ experience}

\subsection{Lexical frequency}

Lexical frequency refers to the frequency with which individual lexical items occur in spoken or written language. Lexical frequency can be measured directly from the input addressed to a language user, as is often done in firstexposure studies and studies on "statistical learning" from input (see Aslin and Newport 2009 for a review). More frequently, however, lexical frequency is estimated from written or oral language corpora (e.g., CELEX), provided, of course, that such corpora are large enough to be representative of a given language. Starting from the early 1950s when it was first shown experimentally that common words are recognized faster than less common words (Howes and Solomon 1951), psychologists and linguists have extensively studied the role of lexical frequency in language learning and use. The assumption underlying most frequency-based approaches is that language users are sensitive to the frequency with which lexical items occur in linguistic input and that the process of language acquisition involves the learning of phonological, morphological, semantic and other types of regularities from input (e.g., Bybee 2008; Pierrehumbert 2003).

With respect to phonological learning, there is a rich body of evidence in first language (L1) literature suggesting that native speakers are sensitive to the relative frequency of phonological regularities in the lexicon. For example, Vitevitch et al. (1997) showed that speakers tend to repeat words containing high-frequency syllables more accurately and more rapidly than words containing low-frequency syllables. Similarly, Frisch et al. (2000) found that listeners recognize nonwords more accurately when they are composed of more frequent 
and therefore more familiar sound combinations, compared to sound combinations that are less frequent. Taken together, these and other findings suggest that native speakers rely on frequency-based, structural properties of the lexicon to perceive and produce language (see Goldberg 2006 and Tomasello 2003 for reviews).

There is some (albeit less extensive) evidence that lexical frequency plays a role in L2 phonological learning as well (e.g., Baker and Trofimovich 2008; Imai et al. 2005; Thomson and Isaacs 2009; but see Flege et al. 1998). For example, Flege et al. (1996) showed that Japanese speakers tended to identify English /r/ and /// with greater accuracy when these consonants occurred in words that were more frequent than their minimal pairs (i.e., when the $/ \mathrm{r} /$ in room was paired with low-frequency loom, or the /1/ in lip was paired with low-frequency rip). In another study, Bradlow and Pisoni (1999) found that L2 learners were more likely to accurately identify high-frequency words with few similar-sounding lexical neighbors (e.g., work or long) than low-frequency words with many lexical neighbors (e.g., hoot or moan). These findings align well with results of variationist studies that have shown effects of lexical frequency on variability in L2 interlanguage (Langman and Bayley 2002; Regan 1996) and are consistent with frequency-based models of L1 and L2 variation (Bybee 2008; Ellis 2008).

When discussing effects of experience in L2 phonological learning, lexical frequency could be used as a measure of language experience in terms of the input learners receive. The logic here is that certain aspects of L2 phonology (e.g., sounds, stress patterns, intonation contours) are easier to learn from frequent exposure to them in the input. Therefore, the frequency of individual words or longer chunks of discourse which include these particular sounds, stress patterns, or intonation contours could serve as a measure of language experience. Put differently, the more frequently an L2 learner experiences a given phonological pattern in the input, as estimated through lexical frequency counts, the more accurately the learner will perceive and produce this pattern. However, equating experience with lexical frequency in such a manner is problematic for several reasons. One reason is that lexical frequency counts offer only estimates of exposure to linguistic input based on large-scale corpora; these estimates may not reflect language users' actual experience with particular lexical items (Balota et al. 2001). This issue is especially problematic in cases when text-based frequencies are used as estimates of exposure to spoken language. Another reason is that lexical frequency could interact with other measures of experience, which would make it inadequate, when considered alone, as an index of linguistic experience.

The last point could be illustrated by using the data from the study by Trofimovich et al. (2007). These researchers investigated the learning of voiced interdental fricative / // (as in mother) by francophone learners of English. The 


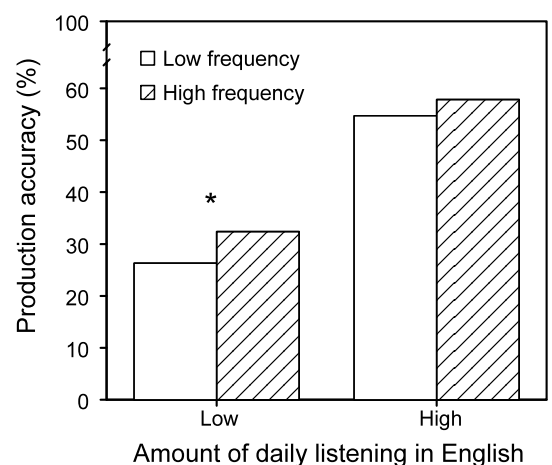

Figure 2. English /ð/ production accuracy for learners with high $(n=20)$ and low $(n=$ 20) amount of daily L2 use in listening, plotted as a function of the frequency with which contextual instances of English / // occur in the BNC spoken corpus (based on Trofimovich et al. 2007). The bars represent averages across 35 tokens of English /ð/ in less frequent lexical contexts (log-based frequency range: 0-2) and 38 tokens of English $/ \partial /$ in more frequent lexical contexts (log-based frequency range: 2.1-4.6).

results of this study showed that the learners' accuracy in producing /ð/ was determined by a combination of two psycholinguistic factors. One factor was lexical frequency, which was estimated from a large-scale corpus of spoken language. The other was cross-language similarity and was based on learners' own judgments of how similar English /ð/ was to French consonants. As part of that study, Trofimovich et al. also obtained learners' judgments of how often they were exposed to English on a daily basis in several modes, including listening. Figure 2 shows the learners' /ð/ production data reanalyzed as a function of lexical frequency and learners' daily amount of listening done in English. Lexical frequency estimates were obtained from the British National Corpus (BNC) database of spoken English. For example, directing the, choose the, and seek the represented contextual instances of English /ð/ that were relatively rare in the corpus, while other, to the, and in the represented those that were common. Learners' amount of daily listening in English was estimated in percentage points on a Likert-type rating scale (0-100\%).

Figure 2 shows that overall the learners who had been involved in daily listening activities more extensively on a daily basis (30-100\% of the time) produced the English /ð/ more accurately than the learners who had been involved in listening less extensively (0-20\% of the time). Thus, for these learners, larger amounts of L2 listening appear to be associated with greater /ð/ production accuracy. However, lexical frequency seemed to influence learner accuracy only for the learners with low amounts of daily L2 listening. These learners produced English /ð/ more accurately when it occurred in more fre- 
quent as opposed to less frequent lexical contexts (e.g., in do that vs. choose the $), t(19)=5.50, p<.0001$. In contrast, the learners with high amount of L2 listening did not differ statistically in how accurately they produced English /ð/ in more and less common lexical contexts, $t(19)=2.19, p=.08$.

The finding illustrated in Figure 2 suggests that positive effects of lexical frequency in L2 phonological learning may be most pronounced in situations where learners either do not have extensive opportunities to use their L2 or they choose (for one reason or another) not to avail themselves of these opportunities. From a theoretical standpoint, this result is compatible with theoretical views that relate frequency of exposure to performance in a variety of domains, both linguistic and non-linguistic. This relationship can be described by the power law of practice, which states that effects of frequency on performance are greatest early in the learning and that increased repetition after a certain point yields only "diminishing returns" (e.g., DeKeyser 2001). From a pedagogical viewpoint, this result implies that providing learners with input containing increased repetitions of targeted phonological features, especially in contexts where exposure to the $\mathrm{L} 2$ is limited, could lead to benefits for their L2 production (see Collins et al. 2009 for additional justifications).

\subsection{Attention to form}

The construct of attention is central to the field of cognitive psychology, where attention typically refers to either the process of selecting relevant information to complete a given task or to a pool of processing resources required for task completion (Kramer et al. 2007). In the field of L2 acquisition, however, the construct of attention is frequently discussed in terms of attention to form, which refers to a focus on formal aspects of language (e.g., morphological markings, syntactic rules, or specifics of pronunciation). Techniques which draw learners' attention to form are based on the assumption that learners may find it difficult to attend to some linguistic features in the input during meaningful communication because these features (e.g., third person singular -s in English) are non-salient, infrequent, or communicatively redundant. Therefore, drawing learners' attention to such features might offer learners an opportunity to "notice" them. This, in turn, increases the likelihood that learners will perceive the discrepancy between the linguistic feature in the input and their own (often non-targetlike) conception of it (Doughty 2001; Schmidt 2001; see Spada and Lightbown 2008 for a review of pedagogical research).

Attention to form in L2 phonological learning can also be studied from a psycholinguistic (processing) perspective. For example, Trofimovich (2008) used auditory priming as a methodology to study how L2 learners process spoken words under different attentional conditions (see also Trofimovich and Gat- 
bonton 2006). In a typical auditory priming experiment, participants are first exposed to a set of spoken words and then are tested on another set containing both words that were previously heard and words that are new to the task (see McDonough and Trofimovich 2008 for various uses of priming methods in $\mathrm{L} 2$ research). A common finding here is that participants show a repetition effect, responding faster to previously heard words compared to new words. This repetition effect has two important characteristics. First, it originates at the level of perceptual processing (Kolers 1975), that is, processing requiring a listener to rely on phonological forms of words. Second, the repetition effect is long-lasting, shown to persist over delays of several weeks (Goldinger 1996). Thus, the repetition effect suggests that listeners can "learn" something about phonological forms of words and can draw on this knowledge to facilitate their subsequent experience with the same words.

Trofimovich (2008) compared repetition effects of this kind for Chinese learners of English in two conditions: when learners' attention was directed to the meanings of words being heard and when learners simply heard the words without any attentional orientation. The prediction there was that attention to meaning, compared to no attentional orientation, would interfere with learners' processing of the phonological forms of words and would, as a result, reduce repetition effects. Results indeed showed that attention to meaning reduced the magnitude of repetition effects. This finding was the most pronounced for repeated words spoken in a different voice (e.g., wonderful spoken by a male and repeated later by a female). Apparently, when learners' attention is drawn to the meaning of words, learners may not be able to benefit from nonidentical repetitions of the same word in the same way that they do when a word is repeated twice by the same speaker. Put differently, learners likely get distracted by differences in speakers' voices (e.g., voice height, voice quality) and are unable to focus on the important phonetic properties that signal the identity of the spoken word. This psycholinguistic finding, Trofimovich argued, was equivalent to a situation typical of many L2 learning contexts: learners are perfectly able to understand a familiar speaker (e.g., their teacher) but have difficulty understanding a new speaker, even when the content of what is being said is well known.

Figure 3 shows the data from Trofimovich (2008) that are relevant to the present discussion of experience effects in L2 phonological learning. In this figure, the learners' repetition effects from the auditory priming experiment are plotted as a function of their self-rated amount of daily experience with English through listening. As was discussed earlier, the repetition effect was a measure of learners' sensitivity to repeated phonological information in spoken words. It was computed by subtracting the learners' reaction times for repeated words from their reaction times for unrepeated words. Thus, a positive repetition effect is indicative of a processing facilitation, while a negative repetition effect 


\section{Pavel Trofimovich}
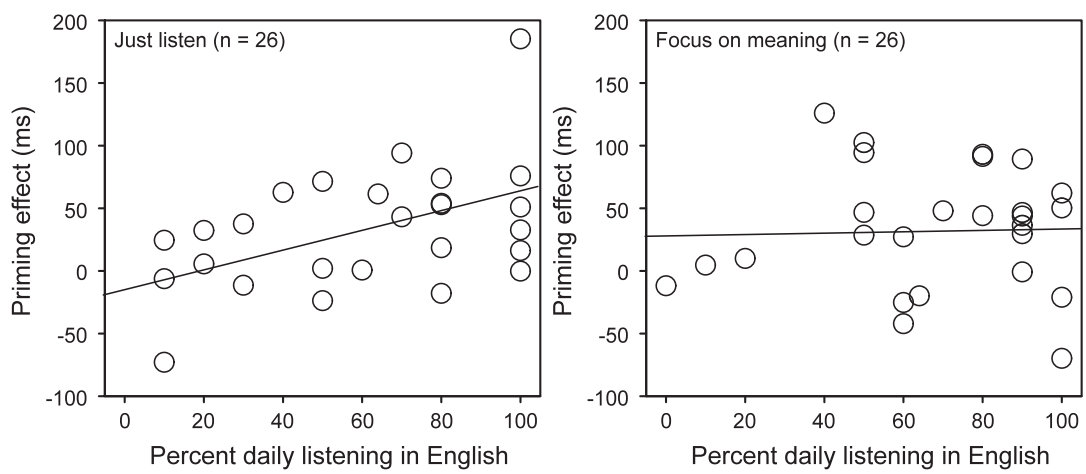

Figure 3. The relationship between Chinese learners' daily experience with English through listening (0-100\% scale) and their repetition priming scores (in milliseconds) for identical repetitions of spoken L2 words, with a regression line showing the best fit to the data (based on Trofimovich 2008)

suggests a processing slowdown. As this figure shows, for the learners who experienced spoken words with no attentional orientation imposed (the just listen condition), there was a significant positive correlation between the magnitude of the repetition effect and amount of daily listening, $r(24)=.45, p=.01$. A greater amount of daily listening in English was associated with a larger repetition effect. In contrast, for the learners who attended to the meaning of spoken words (the focus on meaning condition), there was no such association $r(24)=.03$, n.s.

The finding illustrated in Figure 3 suggests that L2 learners' psycholinguistic (processing) benefits that arise as a consequence of repeated experience with spoken words tend to be associated with learners' L2 use. It is possible that larger amounts of L2 listening enabled the learners to become more sensitive to phonological forms of $\mathrm{L} 2$ words, leading to greater processing benefits. It is also possible, of course, that those learners who showed larger processing benefits were those who tended to use their L2 to a greater extent. Whatever the precise direction of this relationship, there was a link between psycholinguistic processing and L2 experience. However, this link appeared to be absent in situations when the learners experienced spoken L2 words under instructions to attend to word meaning. In these circumstances, the learners were simply unable, for a variety of reasons, to draw on their language experience as they were processing L2 words. These reasons may include constraints of working memory, inability to allocate attention efficiently, or complexity of L2 input (see Trofimovich 2008 for further discussion). The important finding here is that attentional orientation at the time of processing interacts with learners' language experience, thereby shaping the role of experience in L2 phonological learning. 


\subsection{Ethnic group identity}

Language learning cannot be considered outside its social contexts. This implies that a number of social variables (e.g., gender, ethnicity, attitudes) can have a measurable impact on language learning, including L2 phonological learning. Of the many social variables, ethnic identity has the potential to influence both the course and the outcomes of L2 learning in significant ways (Pavlenko and Blackledge 2004). The reason for this is that in order to learn an L2, individuals or groups of individuals come into contact with other individuals or groups, increasing the chances that matters of personal and group identity become salient. Ethnic identity can be broadly defined as a subjective experience of being a part of an ethnic group (Ashmore et al. 2004), and in the case of L2 learning, the ethnic groups in question are learners' own (ancestral) ethnic group and the target language (L2) community.

There is relatively little research documenting how L2 learners' identification with their own ethnic group and with the L2 community impacts language learning outcomes. For instance, for francophone speakers of English in Canada, Taylor et al. (1977) showed a negative relationship between these speakers' proficiency in English and the extent to which they perceived learning English as a means of linguistic assimilation. For these speakers, a higher degree of perceived threat to the survival of their group was associated with lower L2 proficiency. This situation is relevant to what some researchers call subtractive bilingualism or assimilation (Giles et al. 1977; Lambert 1978). In cases of assimilation, individuals (usually members of a minority group) acquire the language of a majority group and often replace their own language and culture with the language and culture of the majority group. As the findings from Taylor et al. suggest, individuals may refrain (overtly or covertly) from acquiring an L2 to avoid assimilation, especially if they fear that the vitality of their ethnic group is threatened. However, other researchers showed positive links between learners' ethnic group identity and their L2 outcomes. For instance, for Russian and Hebrew learners of English in Israel, Ellinger (2000) found that a stronger sense of ethnic group identity was associated with higher L2 proficiency. This situation exemplifies additive bilingualism or integration (e.g., Giles et al. 1977). In cases of integration, individuals add a new language and culture without losing their own.

The relationship between ethnic identity and L2 phonological learning has recently been studied by Gatbonton and her colleagues (Gatbonton and Trofimovich 2008; Gatbonton et al. 2010; Segalowitz et al. 2009). These researchers focused on ethnic group affiliation (EGA), a construct that in addition to identification with a particular ethnic group also includes an emotional component (e.g., pride and loyalty towards one's ethnic group). Gatbonton and Trofimovich (2008) collected reactions to a variety of EGA statements from 59 fran- 
cophone learners of English from Quebec and then submitted these responses to an exploratory factor analysis. This analysis yielded several aspects of the EGA construct that could potentially influence L2 learning outcomes. These aspects included strength of identification with one's ethnic group, feelings of pride and loyalty toward one's group, importance of language in expressing group identity, and support for the group's sociopolitical aspirations. Gatbonton and Trofimovich then examined whether these four aspects of the EGA construct were related to learners' L2 pronunciation, using listener-based measures of accentedness, comprehensibility, fluency, and global L2 ability.

Gatbonton and Trofimovich's (2008) results revealed several strong associations between different EGA constructs and learners' L2 pronunciation. Notably, there was a strong negative association between several pronunciation measures and the political aspect of the EGA. In essence, the learners who expressed stronger political views (e.g., support for Quebec's independence from Canada) were rated as being more accented, less comprehensible, less fluent, and less proficient overall. There was also a positive association between the strength of the learners' identification with their ethnic group and their overall L2 ability. In particular, the learners who had a double-positive orientation, that is, a positive orientation towards their own ethnic group and the L2 community, were rated as more proficient in English. Taken together, these findings show that different aspects of ethnic identity can have positive and negative associations with measures of L2 pronunciation accuracy (see Gatbonton et al. 2010 for similar findings using other measures of $\mathrm{L} 2$ pronunciation).

One noteworthy aspect of these findings is that the relationship between ethnic identity and L2 phonological learning is not direct. Rather, this relationship appears to be mediated by language experience. Gatbonton and Trofimovich (2008) showed this by statistically removing the learners' self-rated amount of L2 use from the associations between different aspects of ethnic identity and $\mathrm{L} 2$ pronunciation measures. When language use was statistically partialled out, all these associations vanished, which suggested that language use was a variable common to ethnic identity factors and pronunciation measures. There are several interpretations of this finding. It is possible, for example, that those individuals who espouse strong political views regarding their ethnic group choose not to interact with members of an L2 group, especially if there are sociopolitical tensions between the groups. As a result, these individuals do not engage in the kinds of activities that would help them improve their L2 pronunciation ability. ${ }^{1}$ It is also possible that individuals whose $\mathrm{L} 2$ ability is relatively

1. It is also possible that at least some francophone speakers choose to transfer certain features of their L1 into their English speech as a way of maintaining their L1 identity. These and other issues are discussed further in Gatbonton and Trofimovich (2008). 


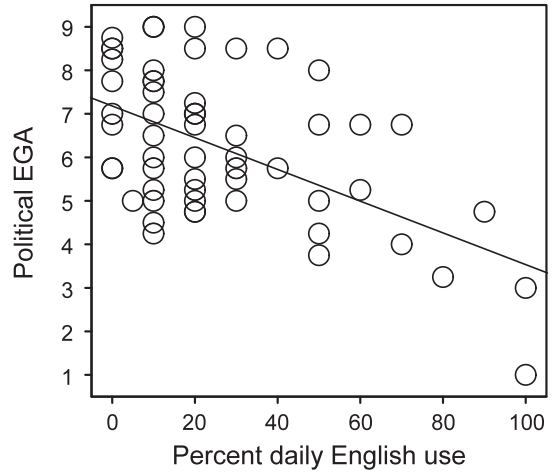

Figure 4. The relationship between francophone learners' $(n=59)$ daily experience with English (0-100\% scale) and their scores on the political aspect of the EGA construct $(1=$ weaker views, $9=$ stronger views $)$, with a regression line showing the best fit to the data (based on Gatbonton and Trofimovich 2008)

low tend to avoid contact with members of an $\mathrm{L} 2$ group precisely because these individuals are unable to interact efficiently in their L2. Consequently, having little contact with members of another group does not allow these individuals to re-evaluate their otherwise strong political views regarding this group.

Whatever the nature of the relationship between ethnic identity and L2 pronunciation, one result reported by Gatbonton and Trofimovich (2008) is clear: strong support for sociopolitical views of one's ethnic group is associated with lower levels of L2 use. This finding is illustrated graphically in Figure 4. This figure shows a scatterplot of the learners' political EGA scores plotted as a function of the learners' daily L2 use. There is a significant negative association between these two variables, $r(57)=-.56, p<.0001$. It is unclear whether this association, which is found in Quebec where political issues surrounding language are salient, would obtain in other contexts with no obvious controversy surrounding language. Nevertheless, even this single example demonstrates that strong ethnic identity views may influence, directly or indirectly, the extent to which learners engage in L2 use. Assuming that greater amounts of L2 experience lead to better learning outcomes, ethnic identity, therefore, has the potential to influence these outcomes.

\section{Theoretical frameworks}

It is clear from the preceding discussion that several factors can interact with language experience, thereby shaping its role in L2 phonological learning. These factors include variables related to training (e.g., type of instruction), 
input (e.g., lexical frequency), cognitive processing (e.g., attention to form), and social context of learning (e.g., ethnic identity). One challenge for L2 researchers is to conceptualize the influence of these and potentially many other variables within coherent and testable theoretical frameworks which link language input and language experience to L2 learning outcomes.

There are several existing theoretical proposals that are promising in this respect. For example, in the field of social psychology, the Willingness to Communicate framework developed by McIntyre and his colleagues (McIntyre et al. 1998) explains a learner's choice to engage in communication in an L2 through a variety of cognitive, social, and experiential factors. Similarly, Clément's Social Context model (Clément 1980; Clément and Kruidenier 1985) draws on such variables as L2 confidence, L2 competence, and L2 identity to describe intergroup contact. More recently, Clément et al. (2003) provided empirical data supporting a framework based on a combination of these two models. In the combined model, frequency and quality of L2 contact predict L2 confidence, which is related to both willingness to communicate and identity. These two factors, in turn, both predict frequency of L2 use. It will certainly be worthwhile exploring the applicability of social-psychological models of L2 use, including the model described by Clément et al., to different $\mathrm{L} 2$ learning contexts (e.g., classroom, naturalistic, study abroad). It will also be worthwhile to extend such models to explain various aspects of L2 phonological learning, for instance, variability in phonological development or acquisition of specific aspects of L2 phonology (see Howard et al. 2006 and Mougeon et al. 2004 for some work in this area).

There are also several multidimensional frameworks that focus on L2 phonological learning specifically. For example, Segalowitz and his colleagues (Segalowitz et al. 2009) recently proposed a conceptualization of L2 phonological learning that includes several cognitive and social influences. In this framework, ethnic identity is part of a larger motivation system which determines whether and to what extent learners engage in L2 use. L2 use is important because it provides learners with opportunities to tune their perceptual and cognitive systems for the processing of L2 input. This cognitive and perceptual tuning, according to Segalowitz et al., is driven by several psycholinguistic variables, which include frequency (i.e., how often a particular phonological target occurs in an L2) and cross-language similarity (i.e., perceptual differences between L1 and L2 that determine the ease or difficulty of certain aspects of L2 phonology). Thus, in this framework, ethnic identity and motivational variables shape particular patterns of $\mathrm{L} 2$ use. L2 use, in turn, impacts language learning outcomes by allowing learners to practice their cognitive processing skills through L2 input and/or output.

Moyer's (2004a, 2009) integrated view of critical influences in SLA exemplifies another multidimensional framework relevant to understanding L2 
phonological learning. Moyer places learners' experience with L2 input, which she calls "strategic use of input", at the centre of her framework. Strategic use of input refers to learners' choices in how and when they take advantage of the available input in accordance with their intentions, orientations, and cognitive styles. Moyer's framework also specifies several clusters of influences that shape how learners use language input. These clusters include cognitive influences (which involve instructional variables, learner strategies and would also include attention to form), social influences (which encompass different language contact domains and situations of language use), and psychological influences (which involve attitudes, motivations, and identity issues). Moyer is deliberately vague in describing the precise contributions of these different factors to L2 phonological learning because these contributions are arguably specific to each learning context. At least one avenue for future research, therefore, would be to provide more refined descriptions of how different factors shape L2 phonological learning in specific learning contexts. This will allow researchers to use theoretical frameworks (such as the ones described by Segalowitz et al. and Moyer) not solely as descriptive tools but also as sources of empirically testable hypotheses.

\section{Reciprocal causation and Matthew effects}

Theoretical frameworks aside, the foregoing discussion of different sources of influence on language experience thus far has been rather vague in terms of the precise nature of the relationships between L2 experience and various other variables. With respect to learners' sensitivity to phonological forms of words, for example, it was argued that larger amounts of L2 listening could help learners become more sensitive to phonological forms of words. Alternatively, it was suggested that being more sensitive to phonological word forms could also make it easier for learners to communicate in their L2 and as a result to use it more frequently. Of course, one reason for this ambiguity stems from the fact that most evidence presented in this paper is primarily based on correlations, which by definition only imply an association between variables, not necessarily causal relationships.

However, a more plausible reason for the difficulty in establishing the precise nature of the relationships between L2 experience and other factors is that these relationships are likely recursive and could therefore be described in terms of reciprocal causation, meaning that potential causal links are running in both directions. In psychological research, reciprocal causation could be described in terms of Matthew effects after a Biblical quote from Matthew: "For everyone who has will be given more, and he will have an abundance. Whoever does not have, even what he has will be taken from him" (Matthew 25: 29). 
The Matthew effect is defined as "... the amplification of any initial advantage (e.g., economic resources, health status, cognitive ability) that leads to cumulative differences that widen preexisting gaps" (Ceci and Papierno 2005: 149; see Walberg and Tsai 1983). Simply put, an early success with a particular skill gives an individual an advantage later, compared to individuals who do not have an advantageous experience with this skill early on. With respect to language, Matthew effects can be exemplified through research on the development of reading skills in both L1 (e.g., Stanovich 1986) and L2 (e.g., Pulido 2003). The Matthew effect in reading refers to the reciprocal relationship between, for example, vocabulary knowledge and reading comprehension. Those readers who have larger vocabularies tend to read extensively, increasing their knowledge base. In contrast, other readers for whom reading comprehension is problematic because their vocabulary knowledge is low are likely to avoid reading and as a result will keep falling behind (e.g., Carreker et al. 2007; see Manzo 2003 for evidence against Matthew effects in education).

It is likely that the relationship between L2 phonological learning and L2 experience also involves self-reinforcing bidirectional processes described by Matthew effects. Those learners who reach a certain threshold of L2 pronunciation ability are often those who avail themselves of different opportunities to use their L2 because understanding and producing speech causes them relatively little difficulty. Opportunities for L2 use, in turn, provide these learners with ample practice with their language skills, which helps improve their L2 pronunciation further. However, other learners for whom L2 pronunciation (and more broadly, L2 speaking) poses difficulty will avoid opportunities to use their L2 precisely because listening and speaking in an L2 proves to be a laborious and grueling task. These learners are often those who tend to fossilize in their L2 pronunciation learning, frequently despite great effort, time, and money spent on language learning (for examples of self-reinforcing learning cycles, see Kennedy and Trofimovich 2010; Moyer 2004b; Segalowitz 2010: Ch. 5; Wray 2002: Ch. 9).

If the outcomes of L2 phonological learning and L2 experience are indeed interlocked through reciprocal causation and can be described in terms of Matthew effects, then how do other variables that shape the role of experience (e.g., type of instruction, lexical frequency, attention to form, ethnic identity) factor into this relationship? One possibility is that these variables play a moderating role in the relationship between L2 learning outcomes and L2 experience. Put differently, all these variables have the potential to impact the self-reinforcing reciprocal relationships between L2 learning outcomes and L2 experience. For example, for the "rich who get even richer", a particular type of instruction (e.g., comprehension-based training described in Lightbown 1992 and Trofimovich et al. 2009), increased repetitions of targeted phonological features, opportunities to attend to form, and a learning context that is non- 
threatening to learners' sense of ethnic identity will only enhance the already positive self-reinforcing links between L2 phonological learning and L2 experience. In contrast, for the "poor who get even poorer", these factors (individually or in combination) may be crucial in breaking, if not completely eliminating, the self-reinforcing downward spiral negatively affecting both L2 learning outcomes and patterns of L2 use.

\section{Future research}

In his description of Matthew effects in reading, Stanovich (1986) identified several kinds of possibilities in which self-reinforcing, reciprocal relationships can unfold. He termed one possibility an active organism-environment interaction. This refers to the fact that individuals actively "select, shape, and evoke their environments" as opposed to simply being influenced by the environment (p. 381; see Scarr and McCartney 1983). This scenario is compatible with the relationships between the outcomes of L2 phonological learning and L2 experience which were discussed in the previous section. In this scenario, learners are active agents who shape their environment by choosing to avail themselves of the opportunities to use their L2 or to abstain from these opportunities.

Stanovich (1986) also described the case of a passive organism-environment correlation, which refers to largely unavoidable consequences of external factors over which individuals have little control or which are determined by a larger social context. In reading research, such external factors include, for example, being raised in a less socioeconomically advantaged area or being schooled in an environment that has more intellectually and emotionally disadvantaged children. This scenario has interesting ramifications for understanding the relationship between language use and language learning outcomes. This is because certain decisions affecting L2 exposure and use may not be under learners' control (e.g., the choice of a particular teaching methodology in a classroom or a sociopolitical context in which learners find themselves). In future research, it will be important to clearly separate the influences on L2 phonological learning and use that are clearly within active control of the learner from those that are beyond the learner's control.

Another fruitful area of future research into effects of experience in L2 phonological learning might involve investigations of thresholds of ability. The idea here is that there are certain thresholds of linguistic and cognitive abilities that enable learners to benefit from the self-reinforcing, positive links between L2 phonological learning and L2 experience. Simply put, learners must achieve a certain level of L2 pronunciation skill or perhaps must accrue a certain amount of L2 experience so that they can enjoy the reciprocal effects of experience on learning (see Krashen 1985 for his related Input Hypothesis). The 
idea of thresholds of ability or experience is not new. For example, thresholds of L2 ability have been discussed in L2 reading (e.g., Cziko 1980) and listening (e.g., Vandergrift 2006), while thresholds of language use have been proposed to explain language change in minority language situations (e.g., Mougeon et al. 2005). However, thresholds of ability and threshold levels of L2 use have not yet been explored in L2 pronunciation research. Identifying thresholds of ability will likely require investigating L2 phonological learning over time (see Snow and Hoefnagel-Hoehle 1978 and Aoyama et al. 2008 for rare examples of longitudinal studies on L2 phonological learning), especially because detecting reciprocal causation and Matthew effects can only be done through longitudinal research. These and other future investigations will help clarify precisely how and why language experience, along with many different factors that interact with it, matter in L2 phonological learning.

\section{Acknowledgements}

The research reported in this paper was supported by grants from Social Sciences and Humanities Research Council of Canada (SSHRC) and Fonds québécois de la recherche sur la société et la culture. The author would like to thank Elizabeth Gatbonton and Norman Segalowitz for many intellectually stimulating and enjoyable collaborations over the years, and Martin Howard, Sarita Kennedy and two anonymous reviewers for their insightful comments on earlier drafts of this paper.

Concordia University, Montréal 〈pavel.trofimovich@concordia.ca〉

\section{References}

Aoyama, Katsura, Susan G. Guion, James Emil Flege, Tsuneo Yamada \& Reiko Akahane-Yamada. 2008. The first years in an L2-speaking environment: A comparison of Japanese children and adults learning American English. International Review of Applied Linguistics 46(1). 61-90.

Ashmore, Richard D., Kay Deaux \& Tracy McLaughlin-Volpe. 2004. An organizing framework for collective identity: Articulation and significance of multidimensionality. Psychological Bulletin 130(1). 80-114.

Aslin, Richard N. \& Elissa L. Newport. 2009. What statistical learning can and can't tell us about language acquisition. In John Colombo, Peggy McCardle \& Lisa Freund (eds.), Infant pathways to language: Methods, models, and research disorders, 15-29. New York: Psychology Press.

Baker, Wendy \& Pavel Trofimovich. 2008. Lexical and segmental influences on child and adult learners' production of second language vowels. Concordia Working Papers in Applied Linguistics 1. 30-54.

Balota, David A., Maura Pilotti \& Michael J. Cortese. 2001. Subjective frequency estimates for 2,938 monosyllabic words. Memory and Cognition 29(4). 639-647. 
Bradlow, Ann R. \& David B. Pisoni. 1999. Recognition of spoken words by native and non-native listeners: Talker-, listener-, and item-related factors. Journal of the Acoustical Society of America 106. 2074-2085.

Bybee, Joan. 2008. Usage-based grammar and second-language acquisition. In Nick C. Ellis \& Peter Robinson (eds.), Handbook of cognitive linguistics and second language acquisition, 216-236. New York: Taylor and Francis.

Carreker, Suzanne H., Graham F Neuhaus, Paul. R. Swnk, Paul Johnson, Mary Jo Monfils \& Mary Lou Montemayor. 2007. Teachers with linguistically informed knowledge of reading subskills are associated with a Matthew effect in reading comprehension for monolingual and bilingual students. Reading Psychology 28. 187-212.

Ceci, Stephen J. and Paul B. Papierno. 2005. The rhetoric and reality of gap closing: When the "have-nots" gain but the "haves" gain even more. American Psychologist 60(2). 149-160.

Clément, Richard. 1980. Ethnicity, contact and communicative competence in a second language. In Howard Giles, William Peter Robinson \& Philip M. Smith (eds.), Language: Social psychological perspectives, 147-154. Oxford: Pergamon.

Clément, Richard, Susan C. Baker \& Peter D. MacIntyre. 2003. Willingness to communicate in a second language: the effects of context, norms and vitality. Journal of Language and Social Psychology 22(2). 190-209.

Clément, Richard \& Bastian G. Kruidenier. 1985. Aptitude, attitude and motivation in second language proficiency: A test of Clément's model. Journal of Language and Social Psychology 4(1). 21-37.

Collins, Laura, Pavel Trofimovich, Joanna White, Walcir Cardoso \& Marlise Horst. 2009. Some input on the easy/difficult grammar question: An empirical study. Modern Language Journal 93. 336-353.

Cziko, Gary A. 1980. Language competence and reading strategies: A comparison of first- and second-language oral reading errors. Language Learning 30. 101-116.

De Graaf, Rick \& Alex Housen. 2009. Investigating the effect and effectiveness of L2 instruction. In Michael H. Long \& Catherine J. Doughty (eds.), Handbook of second language teaching, 726-755. Oxford: Wiley.

DeKeyser, Robert. 2007. Skill acquisition theory. In Bill VanPatten \& Jessica Williams (eds.), Theories in second language acquisition: An introduction, 97-113. Mahwah, NJ: Lawrence Erlbaum.

Doughty, Catherine. 2001. Cognitive underpinnings of focus on form. In Peter Robinson (ed.), Cognition and second language instruction, 206-257. Cambridge: Cambridge University Press.

Ellinger, Bonnie. 2000. The relationship between ethnolinguistic identity and English language for native Russian speakers and native Hebrew speakers in Israel. Journal of Multilingual and Multicultural Development 21(4). 292-307.

Ellis, Nick C. 2008. Usage-based and form-focused language acquisition: The associative learning of constructions, learned attention, and the limited L2 endstate. In Nick C. Ellis \& Peter Robinson (eds.), Handbook of cognitive linguistics and second language acquisition, 372-405. New York: Taylor and Francis.

Flege, James E. 2009. Give input a chance! In Thorsten Piske \& Martha Young-Scholten (eds.), Input matters in SLA, 175-190. Bristol: Multilingual Matters.

Flege, James Emil \& Kathryn L. Fletcher. 1992. Talker and listener effects on degree of perceived foreign accent. Journal of the Acoustical Society of America 91(1). 370-389.

Flege, James E., Elaina M. Frieda, Amanda C. Walley \& Lauren A. Randazza. 1998. Lexical factors and segmental accuracy in second language speech production. Studies in Second Language Acquisition 20(2). 155-187.

Flege, James Emil \& Serena Liu. 2001. The effect of experience on adults' acquisition of a second language. Studies in Second Language Acquisition 23. 527-552. 


\section{Pavel Trofimovich}

Flege, James Emil, Grace H. Yeni-Komshian \& Serena Liu. 1999. Age constraints on second language acquisition. Journal of Memory and Language 41. 78-104.

Flege, James Emil, Murray J. Munro \& Ian R. A. MacKay. 1995. Factors affecting strength of perceived foreign accent in a second language. Journal of the Acoustical Societv of America 97. 3125-3134.

Flege, James Emil, Naoyuki Takagi \& Virginia Mann. 1996. Lexical familiarity and Englishlanguage experience affect Japanese adults' perception of /r/ and //. Journal of Acoustical Society of America 99(2). 1161-1173.

Frisch, Stefan A., Nathan R. Large \& David B. Pisoni. 2000. Perception of wordlikeness: Effects of segment probability and length on the processing of nonwords. Journal of Memory and Language 42(4). 481-496.

Gatbonton, Elizabeth \& Pavel Trofimovich. 2008. The ethnic group affiliation and L2 proficiency link: Empirical evidence. Language Awareness 17. 229-248.

Gatbonton, Elizabeth, Pavel Trofimovich \& Norman Segalowitz. 2011. Ethnic group affiliation and pattern of development of a phonological variable. Modern Language Journal.

Giles, Howard, Richard Y. Bourhis \& Donald M. Taylor. 1977. Towards a theory of language in ethnic group relations. In Howard Giles (ed.), Language, ethnicity and intergroup relations, 307-348. New York: Academic Press.

Goldberg, Adele E. 2006. Constructions at work: The nature of generalization in language. Oxford: Oxford University Press.

Goldinger, Steven D. 1996. Words and voices: Episodic traces in spoken word identification and recognition memory. Journal of Experimental Psychology: Learning, Memorv, and Cognition 22. 1166-1183.

Gullberg, Marianne, Leah Roberts \& Christine Dimroth. Forthcoming. What word-level knowledge can adult learners acquire after minimal exposure to a new language? International Review of Applied Linguistics.

Howard, Martin. 2005. On the role of context in the development of learner language: Insights from study abroad research. International Journal of Applied Linguistics 148. 1-20.

Howard, Martin, Isabelle Lemée \& Vera Regan. 2006. The L2 acquisition of a phonological variable: The case of /1/ deletion in French. French Language Studies 16. 1-24.

Howes, Davis H. \& Richard L. Solomon. 1951. Visual duration threshold as a function of wordprobability. Journal of Experimental Psychology 41(6). 401-410.

Imai, Satoru, Amanda C. Walley \& James Emil Flege. 2005. Lexical frequency and neighborhood density effects on the recognition of native and Spanish-accented words by native English and Spanish listeners. Journal of Acoustical Society of America 117. 896-906.

Jia, Gisela \& Doris Aaronson. 2003. A longitudinal study of Chinese children and adolescents learning English in the United States. Applied Psvcholinguistics 24(1). 131-161.

Kennedy, Sara \& Pavel Trofimovich. 2010. Language awareness and second language pronunciation: A classroom study. Language Awareness 19(3). 171-185.

Kolers, Paul A. 1975. Memorial consequences of automatized encoding. Journal of Experimental Psychology: Human Learning and Memory 1: 689-701.

Kramer, Arthur F., Douglas A. Wiegmann \& Alex Kirlik. 2007. Attention: From Theory to Practice. New York: Oxford University Press.

Krashen, Stephen D. 1985. The input hypothesis: Issues and implications. London: Longman.

Lambert, Wallace 1978. Cognitive and socio-cultural consequences of bilingualism. Canadian Modern Language Review 34. 537-547.

Langman, Juliet \& Robert Bayley. 2002. The acquisition of verbal morphology by Chinese learners of Hungarian. Language Variation and Change 14(1). 55-77.

Lightbown, Patsy M. 1985. Input and acquisition for second language learners in and out of classrooms. Applied Linguistics 6. 263-273. 
Lightbown, Patsy M. 1992. Can they do it themselves? A comprehension-based ESL course for young children. In Robert Courchêne, Jennifer St John, Christiane Thérien, \& John I. Glidden (eds.), Comprehension-based second language teaching, 353-370. Ottawa: University of Ottawa Press.

MacIntyre, Peter D., Richard Clément, Zoltán Dörnyei \& Kimberly A. Noels. 1998. Conceptualizing willingness to communicate in a L2: A situational model of L2 confidence and affiliation. The Modern Language Journal 82. 545-562.

Manzo, Anthony V. 2003. Literacy crisis or Cambrian period? Theory, practice, and public policy implications. Journal of Adolescent and Adult Literacy 46(8). 654-661.

McDonough, Kim \& Pavel Trofimovich. 2008. Using priming methods in second language research. New York: Routledge.

Mougeon, Raymond, Katherine Rehner \& Terry Nadasdi. 2004. The learning of spoken French variation by immersion students from Toronto, Canada. Journal of Sociolinguistics 8(3). 408 432.

Mougeon, Raymond, Terry Nadasdi \& Katherine Rehner. 2005. Contact-induced linguistic innovations on the continuum of language use: The case of French in Ontario. Bilingualism: Language and Cognition 8(2). 99-115.

Moyer, Alene. 2004a. Age, accent and experience in second language acquisition. Clevedon: Multilingual Matters.

Moyer, Alene. 2004b. Accounting for context and experience in German (L2) language acquisition: A critical review of the research. Journal of Multilingual and Multicultural Development 25(1). 41-61.

Moyer, Alene. 2006. Language contact and confidence in second language listening comprehension: A pilot study of advanced learners of German. Foreign Language Annals 39(2). 255-275.

Moyer, Alene. 2009. Input as a critical means to an end: Quantity and quality of experience in L2 phonological attainment. In Thorsten Piske \& Martha Young-Scholten (eds.), Input matters in SLA, 159-174. Bristol: Multilingual Matters.

Muñoz, Carmen. 2006. Age and the rate of foreign language learning. Clevedon: Multilingual Matters.

Musumeci, Diane. 1997. Breaking tradition: An exploration of the historical relationship between theory and practice in second language teaching. New York: McGraw Hill.

Palmer, Harold E. 1968 [1917]. The scientific study and teaching of languages. London: Oxford University Press.

Pavlenko, Aneta \& Adrian Blackledge. 2004. Negotiation of identities in multilingual contexts. Clevedon: Multilingual Matters.

Pérez-Vidal, Carmen \& Maria Juan-Garau. 2009. The effect of study abroad (SA) on written performance. In Leah Roberts, Daniel Véronique, Anna-Carin Nilsson \& Marion Tellier (eds.), EUROSLA Yearbook 9. 269-295.

Pierrehumbert, Janet B. 2003. Probabilistic phonology: Discrimination and robustness. In Rens Bod, Jennifer Hay \& Stefanie Jannedy (eds.), Probabilistic Linguistics, 177-228. Cambridge: MIT Press.

Piller, Ingrid. 2002. Passing for a native speaker: Identity and success in second language learning. Journal of Sociolinguistics 6. 179-206.

Piske, Thorsten \& Young-Scholten, Martha. 2009. Input matters in SLA. Bristol: Multilingual Matters.

Pulido, Diana. 2003. Modeling the role of second language proficiency and topic familiarity in second language incidental vocabulary acquisition through reading. Language Learning 53. 233-284.

Purcell, Edward T. \& Richard W. Suter. 1980. Predictors of pronunciation accuracy: A reexamination. Language Learning 30(2). 271-287.

Rast, Rebekah. 2008. Foreign language input: Initial processing. Clevedon: Multilingual Matters. 
Regan, Vera. 1996. Variation in French interlanguage: A longitudinal study of sociolinguistic competence. In Robert James Bayley \& Dennis Richard Preston (eds.), Second language acquisition and linguistic variation, 177-202. Amsterdam: John Benjamins.

Scarr, Sandra \& Kathleen McCartney. 1983. How people make their own environments: A theory of genotype-environment effects. Child Development 54(2). 424-435.

Schmidt, Richard. 2001. Attention. In Peter Robinson (ed.), Cognition and second language instruction, 3-32. Cambridge: Cambridge University Press.

Segalowitz, Norman, Elizabeth Gatbonton and Pavel Trofimovich. 2009. Links between ethnolinguistic affiliation, self-related motivation and second language fluency: Are they mediated by psycholinguistic variables? In Zoltán Dörnyei \& Ema Ushioda (eds.), Motivation, language identity and the L2 self, 172-192. Bristol: Multilingual Matters.

Segalowitz, Norman. 2010. The cognitive bases of second language fluency. New York: Routledge. Snow, Catherine E. \& Marian Hoefnagel-Höhle. 1978. The critical period for language acquisition: Evidence from second language learning. Child Development 49(4). 1114-1128.

Spada, Nina. 1986. The interaction between type of contact and type of instruction: Some effects on the L2 proficiency of adult learners. Studies in Second Language Acquisition 8. 181-200.

Spada, Nina \& Patsy M. Lightbown. 2008. Form-focused instruction: Isolated or integrated? TESOL Ouarterly 42(2). 181-207.

Stanovich, Keith E. 1986. Matthew effects in reading: Some consequences of individual differences in the acquisition of literacy. Reading Research Ouarterly 21(4). 360-407.

Suter, Richard W. 1976. Predictors of pronunciation accuracy in second language learning, Language Learning 26. 233-253.

Taylor, Donald M., Roch Meynard \& Elizabeth Rheault. 1977. Threat to ethnic identity and second language learning. In Howard Giles (ed.), Language, ethnicity and intergroup relations, 99116. New York: Academic Press.

Thompson, Irene. 1991. Foreign accents revisited: the English pronunciation of Russian immigrants. Language Learning 41. 177-204.

Thomson, Ron I. \& Talia Isaacs. 2009. Within-category variation in L2 English vowel learning. Canadian Acoustics 37(3). 138-139.

Tomasello, Michael. 2003. Constructing a language: A usage-based theory of language acquisition. Cambridge, MA: Harvard University Press.

Trofimovich, Pavel. 2008. What do second language listeners know about spoken words? Effects of experience and attention in spoken word processing. Journal of Psycholinguistic Research 37. 309-329.

Trofimovich, Pavel \& Elizabeth Gatbonton. 2006. Repetition and focus on form in L2 Spanish word processing: Implications for pronunciation instruction. The Modern Language Journal 90. 519-535.

Trofimovich, Pavel, Elizabeth Gatbonton \& Norman Segalowitz. 2007. A dynamic look at L2 phonological learning: Seeking psycholinguistic explanations for implicational phenomena. Studies in Second Language Acquisition 29(4). 407-448.

Trofimovich, Pavel, Patsy M. Lightbown, Randall Halter \& Hyojin Song. 2009. Comprehensionbased practice: The development of L2 pronunciation in a listening and reading program. Studies in Second Language Acquisition 31. 609-639.

Vandergrift, Larry. 2006. Second language listening: Listening ability or language proficiency? The Modern Language Journal 90. 6-18.

VanPatten, Bill. 2004. Processing instruction: Theory, research, and commentary. Mahwah, NJ: Lawrence Erlbaum.

Vitevitch, Michael S., Paul A. Luce, Jan Charles-Luce \& David Kemmerer. 1997. Phonotactics and syllable stress: Implications for the processing of spoken nonsense words. Language and Speech 40(1). 47-62.

Walberg, Herbert J. \& Shiow-Ling Tsai. 1983. Matthew effects in education. American Educational Research Journal 20(3). 359-373.

Wray, Alison. 2002. Formulaic language and the lexicon. Cambridge: Cambridge University Press. 